Age, sex, characteristics of injury, and whether analgesia was given to patients in hospital. Values are numbers (\%) of ethnic group unless stated otherwise

\begin{tabular}{|c|c|c|c|c|}
\hline & White $(n=224)$ & Bangladeshi ( $n=42)$ & Other ethnicity ( $n=18$ ) & Ethnicity not recorded ( $n=23$ ) \\
\hline Mean (range) age (years) & $33.8(15-55)$ & $25.9(15-50)$ & $35.1(16-55)$ & $33.5(15-52)$ \\
\hline No of male patients & $146(66)$ & $34(81)$ & $10(59)$ & $12(52)$ \\
\hline \multicolumn{5}{|l|}{ Mechanism of injury: } \\
\hline Fall & $148(67)$ & $31(76)$ & $11(69)$ & $16(70)$ \\
\hline Road traffic accident & $40(18)$ & $4(10)$ & $5(31)$ & $4(17)$ \\
\hline Assault & $5(2)$ & $4(10)$ & $0(0)$ & $1(4)$ \\
\hline Occupational & $27(12)$ & $1(3)$ & $0(0)$ & $2(9)$ \\
\hline \multicolumn{5}{|l|}{ Bone fractured: } \\
\hline Femur & $5(2)$ & $2(5)$ & $2(11)$ & $1(4)$ \\
\hline Humerus & $21(9)$ & $3(7)$ & $1(6)$ & $2(9)$ \\
\hline Radius or ulna & $113(50)$ & $25(60)$ & $5(28)$ & $12(52)$ \\
\hline Tibia or fibula & $85(38)$ & $12(29)$ & $10(56)$ & $8(35)$ \\
\hline Reduction needed & $44(20)$ & $9(22)$ & $3(17)$ & $5(23)$ \\
\hline Admitted & $81(36)$ & $13(31)$ & $7(39)$ & $8(35)$ \\
\hline Analgesia given & $175(78)$ & $34.0(81)$ & $14(78)$ & $20(87)$ \\
\hline
\end{tabular}

factors such as the bone affected, the need for reduction, and rates of admission were broadly similar among the groups. The study was retrospective because we did not want to affect current practice, and we did not measure potential confounding factors. What factors determine prescription of analgesia? Ethnicity could influence pain threshold, communication of pain to healthcare staff, and relationships between patients and staff. A recent review concluded that no ethnic differences were detected in the neurophysiological detection of pain, but there are reports of interethnic variation in the interpretation and expression of pain. ${ }^{23}$ In contrast to Todd et al, however, we found that ethnicity was not a risk factor for underuse of analgesia in isolated long bone fractures in our hospital.
We thank Naomi Barrows, Clinical Effectiveness Unit Project coordinator, for her help with this study.

PY initiated the study and contributed to study design, data analysis, and writing of the paper. DMAC contributed to study design, collected the data, and drafted the paper. TC discussed core ideas and contributed to data interpretation and writing of the paper. PK and EAP contributed to study design, data collection, and analysis. PY is guarantor for the study.

Funding: none.

Competing interests: None declared.

1 Todd KH, Samaroo N, Hoffman JR. Ethnicity as a risk factor for inadequate emergency department analgesia. JAMA 1993;269:1537-9.

2 Zatzick DF, Dimsdale JE. Cultural variations in response to painful stimuli. Pyschosom Med 1990;52:544-57.

3 Greenwald HP. Interethnic differences in pain perception. Pain 1991;44:157-63.

(Accepted 2 January)

\title{
An unexpected present
}

The young woman was clearly visible from the consulting room window, her emaciated frame draped in the tattered remnants of a sari, with a marasmic toddler balanced on her hip. She begged for food and alms, reaching wordlessly through the open windows of the buses parked at the bus stand.

She frequently pointed to the toddler, her eyes eloquent and beseeching. Few could hold out against this poignant appeal, and she made a good living. I watched her every day and noticed her abdomen getting bigger. On my home from work one day, I inquired, "Pregnant?"

"Yes."

"You must go to the municipal hospital. They will give you the tetanus toxoid injections and folic acid supplements. Your child will get free immunisations."

"The municipal hospital is not for people like me."

It was a futile argument. I found myself collecting haematinics and calcium tablets from medical representatives for her. I administered the tetanus toxoid injections, but could not persuade her to undergo any blood tests. So her blood group and HIV status remained unknown.

Six months later, hearing a commotion in the waiting room, I peered out. She was in labour, on the floor, watched in horror by the rest of the patients.

"Can you go somewhere else? This is only a consultation practice. I do not deal with childbirth."

Her only answer was a groan, after which she started to push. Frantic, I cleared the waiting room, and, after the lapse of 10 years, I conducted an amateur delivery, with no implements and no assistance. It was a healthy baby girl.
"Where will you go?"

"You know I have nowhere to go."

This was more than I had bargained for.

"Okay. You can spend the night on the verandah. Do you have a family?"

"No."

That was not possible. Had she sprung up like a weed?

"This birth has to be registered."

"Tomorrow doctor. I cannot move today."

The next morning she had disappeared. The verandah was wiped clean, and she had left me a present. It was caterwauling behind a stone bench, wrapped in a dirty piece of cloth.

There has been no trace of the mother in 15 years. The little present has, in the meantime, grown into a sister for my other children.

Gita Mathai paediatrician in family practice, Vellore, Tamil Nadu, India

We welcome articles of up to 600 words on topics such as A memorable patient, A paper that changed my practice, My most unfortunate mistake, or any other piece conveying instruction, pathos, or humour. If possible the article should be supplied on a disk. Permission is needed from the patient or a relative if an identifiable patient is referred to. We also welcome contributions for "Endpieces," consisting of quotations of up to 80 words (but most are considerably shorter) from any source, ancient or modern, which have appealed to the reader. 